\title{
SOCIAL ECOLOGY AND THEORY OF MIND
}

\author{
Ai MIZOKAWA ${ }^{1)}$ and Asuka KOMIYA ${ }^{2)}$ \\ ${ }^{1)}$ Meiji Gakuin University, Japan \\ ${ }^{2)}$ Kochi University of Technology, Japan
}

\begin{abstract}
Human development is embedded in various social contexts, such as family, peers, and cultures. Since Bronfenbrenner's theoretical work, many developmental psychologists have investigated environmental influences on human development. In this article, we review the research investigating how social environments interactively affect the development of theory of mind (i.e., the ability to attribute mental states to oneself and to others). We first introduce Bronfennbrenner's ecological systems theory of human development. Based on his socio-ecological perspective, we review previous research discussing the relationships between proximal (i.e., parents and siblings) and distal environments (i.e., socio-economic status, culture, and educational system), and the mental state understanding of children. Finally, we discuss future directions of developmental research in this area and potential applications in education.
\end{abstract}

Key words: theory of mind, ecological systems theory, young children

For the past 30 years, theory of mind has been one of the most popular topics of research concerning the social cognition of children. Theory of mind is the ability to attribute mental states, such as knowledge, desire, intents, and beliefs to oneself and to others, and to perceive the distinct mental states of others (Premack \& Woodruff, 1978). By assuming what people know, want, and believe, we can predict the behavior of individuals. Evidence following Premack and Woodruff (1978) have led to the general conclusion that other than human beings, animals including primates, such as chimpanzees, can understand others' mental states to a limited extent (Call \& Tomasello, 2008). Tomasello and his colleagues emphasized the importance of theory of mind for our species, by relating the evolution of theory of mind to the evolution of culture. They pointed out that we can be involved in social learning and inherit cultural heritage, (1) because theory of mind allows us to realize the ignorance of someone else and teach her/him something, and (2) because it also enables us to negotiate and collaborate with each other (e.g., Tomasello, Kruger, \& Ratner, 1993).

Following the initial theory of mind research with chimpanzees (Premack \& Woodruff, 1978), a great deal of studies on theory of mind have been conducted to examine the chronological sequence of its development in human children. Even in infancy, human beings show early signs of awareness of others' mental states. Infants as young as 1-dayold, for example, show signs of unease when they hear another baby crying, suggesting the concern for the emotions they perceive in others (Sagi \& Hoffman, 1976). Moreover,

Correspondence concerning this article should be addressed to Ai Mizokawa, Faculty of Psychology, Meiji Gakuin University, 1-2-37 Shirokanedai, Minato-ku, Tokyo 108-8636, Japan (e-mail: aimizokawa@gmail.com). 
fifteen-month-olds infants look longer at an agent when the agent's actions are different from her/his beliefs (Onishi \& Baillargeon, 2005), and 25-month-olds show an implicit understanding of others' false beliefs (Southgate, Senju, \& Csibra, 2007). Most theory of mind studies with children have focused on the later development of representational (i.e., not implicit) theory of mind in preschool years, which was indexed by success in first-order false belief tasks (Wimmer \& Perner, 1983). These studies have revealed that children in typical development understand first-order false beliefs by 4- to 5-years of age (Wellman, Cross, \& Watson, 2001).

There is a large body of research suggesting positive links among the development of theory of mind, social relationships, and social behaviors. For example, children who are adept at reading the mental states of others are better at communication and social interactions (Slomkowski \& Dunn, 1996; Watson, Nixon, Wilson, \& Capage, 1999), more popular amongst peers (Morino, 2005; Slaughter, Dennis, \& Pritchard, 2002), and more likely to engage in pro-social and empathetic behaviors (Cassidy, Werner, Rourke, Zubernis, \& Balaraman, 2003; Mizokawa \& Koyasu, 2011). On the other hand, impairment of theory of mind enhances the risk of problematic behaviors, such as attention problems and disruptive behavior (Fahie \& Symons, 2003; Hughes, Dunn, \& White, 1998).

Since theory of mind is assumed to have an evolutionary origin and to be a fundamental cognitive process required for every person's social life, the earliest research has focused mainly on how theory of mind develops and its relation to other cognitive functions within an individual. However, a growing body of research has revealed indispensable socioenvironmental influences on the development of theory of mind, such as mother-child relationships (e.g., Dunn, Brown, Slomkowski, Tesla, \& Youngblade, 1991), socioeconomic status (e.g., Cutting \& Dunn, 1999; Jenkins \& Astington, 1996), and culture (Hughes et al., 2014), suggesting the need to consider the role of social environments on the development of theory of mind.

In the present article, we review the research investigating how the environment affects children's theory of mind from a socio-ecological perspective. To provide a theoretical background, we begin by introducing the ecological systems theory (Bronfenbrenner, 1979; Bronfenbrenner \& Morris, 2006), which is one of the most famous theories of development focusing on the multi-system layers of the environment that influence an individual's development. Based on the ecological systems theory, we then review previous research investigating how various aspects of the environment (e.g., family, peers, and cultures) influence children's social cognition. Finally, we discuss future directions of developmental research in this area and potential applications in education.

\section{ECOLOGICAL SYSTEMS THEORY}

In the 1970s, developmental psychologists focused mainly on individual psychological processes, such as perception, motivation, and learning, and paid less attention to the influence of environmental processes. The primary research method used was the experimental laboratory paradigm, which aims to control environmental and contextual 


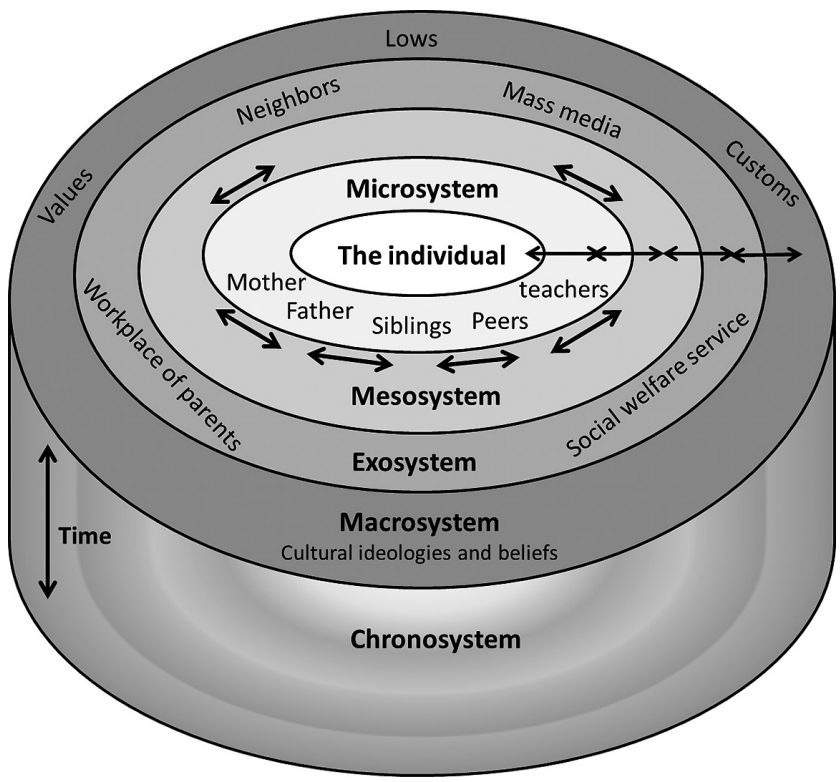

Fig. 1. The structure of the environment in Bronfenbrenner' ecological systems theory

effects, while observational studies, which emphasize ecological validity, were the least employed method (Bronfenbrenner, 1977).

At the time, Urie Bronfenbrenner, an American developmental psychologist, published an influential book, titled "The Ecology of Human Development," in which he challenged the traditional developmental view (Bronfenbrenner, 1979). Bronfenbrenner's view of development was deeply affected by Levin Vygotsky, who investigated child development by emphasizing influences of social contexts and history in the early 20th century (Vygotsky, 1978/1930, 1933, 1935). Like Vygotsky, Bronfenbrenner saw child development as a dialectic between the individual and the environmental context. Bronfenbrenner defined human development as "changes during the life course in enduring patterns of behavior or perception resulting from the interplay of biological characteristics of the person and the environment (Bronfenbrenner \& Crouter, 1983, p. 359)," and stressed the role of environment on individual development.

Bronfenbrenner introduced the idea that children develop within several concentric layers of the socio-cultural context, each of which interactively influences psychological functioning (Fig. 1). He defined the environment as any event or condition outside the organism that affects or is affected by a person's development (Bronfenbrenner \& Crouter, 1983). On the basis of distance to the individual, the environment is differentiated as five layers from the proximal layer to the distal layer: the microsystem, mesosystem, exosystem, macrosystem, and chronosystem. According to Bronfenbrenner (1999; Bronfenbrenner \& Morris, 2006), proximal processes are the "engines of development" and provide the links, the interactions, and the mutual influences between individuals and environments. Their form, power, content, and direction vary with the characteristics of the developing person. 
More specifically, microsystems are settings in which an individual is directly connected at a given moment, such as families (e.g., mother, father, and siblings), peers, or classrooms. Mesosystems comprise an individual's developmental niches which are constituted by two or more separate microsystems, such as marital relationships, parent-peer relationships, and parent-teacher associations (PTAs). Exosystems are composed of contexts that indirectly influence the person's development through the microsystems and/or the mesosystems, such as neighbors, the workplace of parents, the mass media, or social welfare services. Macrosystems are cultural ideologies and beliefs that are more distant but still constrain an individual's environment. Major determinants of macrosystems are education systems, laws, socio-economic status (SES), and cultures. Finally, his later revision of the framework also included the Chronosystem as one of the ecological systems, which reflects the dynamic nature of development in the environment (Bronfenbrenner, 1994, 2005). The Chronosystems encompass change or consistency over time not only in the characteristics of the person but also of the environment in which that person lives (e.g., changes over the life course in family structure, socio-economic status, employment, place of residence, or the degree of hecticness and ability in everyday life; Bronfenbrenner, 1994).

Ecological systems theory emphasizes the interactions across environments and individuals. In fact, most developmental characteristics have multiple determinants, and their effects are not necessarily linearly added. For instance, the attitudes of parents affect how their children feel, think, and behave in a certain situation. At the same time, the attitudes of parents are influenced by various socio-ecological factors, such as whether parents agree with each other's opinions, the extent to which they have social and material resources, or the roles that their cultural environment expects children to play. These factors, importantly, could have interactive effects on the development of children. Bronfenbrenner often referred to Drillien's classic longitudinal studies $(1957,1964)$ which showed the impact of the quality of mother-child interaction at age 2 on the problem behaviors at age 4 as a joint function of birth weight and social class; poor mother-child processes were connected to a child's behavioral problems, especially in low-SES families. Based on these data, Bronfenbrenner suggested that human development cannot be understood without considering various environmental factors and their interactions with each other.

\section{ECOLOGICAL SYSTEMS THEORY AND THEORY OF MIND}

Since Bronfenbrenner's earlier theoretical work was published, there has been a growing body of cross-sectional, longitudinal, and cohort research emphasizing environmental influences on children's development. Moreover, behavioral genetics has shown how environments moderate gene expressions and children's development (e.g., Caspi et al., 2002; Plomin, 1994; Plomin, Reiss, Hetherington, \& Howe, 1994). This accumulated evidence motivated researchers to publish the first handbook devoted to the influence of ecological environments on children's development (Mayes \& Lewis, 2012).

Although the handbook covers various topics in applied contexts, including problematic behaviors, anxiety disorders, maltreatment of children, and social support, it 
lacks a review of environmental effects on more fundamental socio-cognitive process. As noted earlier, the following questions have been the focal issues in developmental psychology: When and how do children aware and understand their own and others' mental states? And how do children interact with their social environment based on their ability to understand mental states? Accumulated evidence in this area implies that there are dynamic relationships between environments and children's social cognition. In this section, we focus on the research investigating theory of mind and review how social environments affect its development from the perspective of ecological systems theory.

\section{Environmental effects on theory of mind}

To investigate the developmental stages of theory of mind, researchers have often examined whether children understand that others have false beliefs, which are different from the child's own beliefs or from actual states, by using the false belief tasks in which a hypothetical character has false beliefs about the location or contents of certain objects (e.g., Baron-Cohen, Leslie, \& Frith, 1985; Gopnik \& Astington, 1988; Wimmer \& Perner, 1983). A meta-analysis of 20 years of theory of mind studies has revealed that children successfully understand others' false beliefs by 4- to 5- years of age (Wellman et al., 2001).

To our knowledge, Dunn and her colleagues (1991) conducted the first study to reveal environmental differences in theory of mind. In their longitudinal study, when their participants were at 33-months-old (time 1), they carried out two observations in the children's home in which normal familial conversations at home were recorded and rated. Seven months later, when the same children reached 40-months-old (time 2), the false belief task and the affective perspective tasks were conducted at home to assess the children's social cognition. As the main result, this study showed that children who had more frequent conversations with their mothers about feelings and causality were more likely to explain the character's action in the task situations correctly 7 months later than those who did not. This study was therefore the first to reveal that social environments could influence the development of fundamental, social-cognitive processes, and it motivated researchers to investigate the relationship between social environments and theory of mind.

In the following segments, we review research that indicates environmental effects on the development of theory of mind. Unlike previous reviews concerning theory of mind (Doherty, 2009; Hughes \& Leekam, 2004; Miller, 2012), we tried to integrate the findings into the ecological system, from the proximal (e.g., family) to the distal (e.g., time) environments, following the model suggested by Bronfenbrenner (1979; Bronfenbrenner \& Crouter, 1983; Bronfenbrener \& Morris, 2006). We believe that our approach can assist in promoting a deeper understanding of how multi-layer ecological environments interactively influence children's socio-cognitive development.

\section{Proximal environment and theory of mind}

Parents. Parents, typically the most proximal environments, have obvious effects on a child's theory of mind development. Following Dunn's longitudinal study (Dunn et al., 1991), abundant subsequent evidence suggests a link between mother-child daily 
conversations and theory of mind development (e.g., Ensor, Devine, Marks, \& Hughes, 2013; Ensor \& Hughes, 2008; Peterson \& Siegal, 1999, 2000; Peterson \& Slaughter, 2003; Ruffman, Perner, \& Parkin, 1999; Ruffman, Slade, \& Crowe, 2002). For example, children with mothers who encourage them to reflect on the victim's perspective in the children's transgression situations performed better on a theory of mind task (Ruffman et al., 1999). Moreover, Ruffman's longitudinal study (Ruffman et al., 2002) with children at three points in time (3-, 3.5-, and 4-years of age) found that the amount of cognitive terms that mothers use (e.g., "think" and "know") predicted children's later theory of mind performance. Ensor and her colleagues replicated their findings and found that the extent to which mothers refer to mental states (i.e., desires and thoughts) when the children were at two-years of age predicted individual differences in the children's social understanding during and after preschool years (Ensor et al., 2013; Ensor \& Hughes, 2008).

Parenting styles also influence children's understanding of others' minds. For example, Pears and Moses (2003) showed that authoritarian parenting, which is a harsh parenting style that utilizes power-assertive techniques including physical punishment, commands, and yelling, was associated with the impairment of children's understanding of false beliefs. Although the direction of the correlation should be carefully interpreted, Hughes, Deater-Deckard, and Cutting (1999) also showed that the objective ratings of parental negative control, such as criticism or physical control of the child, was negatively correlated with theory of mind scores.

Siblings. With regard to the influence of siblings, there are mixed results. Some studies reported that children with siblings better understood theory of mind than children without siblings (Jenkins \& Astington, 1996; Lewis, Freeman, Kyriakidou, MaridakiKassotaki, \& Berridge, 1996; Peterson, 2000; Perner, Ruffman, \& Leekam, 1994; Ruffman, Perner, Naito, Parkin, \& Clements, 1998). Other studies, however, found no effect of siblings on the development of theory of mind (Cassidy, Fineberg, Brown, \& Perkins, 2005; Cole \& Mitchell, 2000; Cutting \& Dunn, 1999; Peterson \& Slaughter, 2003). One of the reasons for these mixed findings might be that the development of theory of mind depends not simply on how many siblings children have, but on how children interact with their sibling(s).

Interactions between individual characteristics and proximal environments. It is important to note that several of the findings mentioned above showed an interplay between children's individual characteristics and their environments. For example, Jenkins and Astington (1996) found that family size has a very small effect on theory of mind when a child's language ability is high, whereas there is a strong family size effect when their language ability is low. Likewise, Hughes et al. (1999) reported a sex difference in parenting styles, showing that warm parenting styles (i.e., positive affect, closeness, parental knowledge of the children, and enjoyment of the parenting role) had a positive impact on understanding of mind, especially among girls, whereas the severity of discipline (i.e., severe, strict, usually involving physical punishment) was positively associated with understanding of mind among boys. These findings support Bronfenbrenner's (1979) thesis, emphasizing the interaction between environments and individuals.

Interactions between proximal environments. Interactions between two or more 
proximal environments (mesosystem) also affect child development. Dunn and her colleagues (1991) have found associations between the children's cooperative interactions with an older sibling at 33-months-old and their later performance on tests of emotion and false belief understanding administered at 40 months of age. Children's performance in these tests was also influenced by the relationships between the mother and older sibling and between the siblings, demonstrating the influence of complex interactions between proximal environments.

Moreover, there is plenty of evidence showing that quality of marital relationships affects parenting behaviors. Research on the links between marriage and parenting (i.e., how marriage affects parenting, how parenting affects marriage, and how children affect both parenting and marriage) has been examined in psychological research since the 1980s (Belsky, 1981; Emery, 1982), and empirical studies have documented associations between these dyads. For example, Goldberg and Easterbrooks (1984) found that good marital quality was associated with optimal toddler functioning and sensitive parenting. The findings of several longitudinal studies support a causal link between marital quality and parenting dimensions (e.g., Belsky, Youngblade, Rovine, \& Volling 1991; Cowan \& Cowan, 1992), suggesting that parental relationships, which are classified as mesosystems, may influence a child's socio-cognitive development through parenting styles (microsystem).

\section{Distal environments and theory of mind}

Socio-economic status. One of the most prominent examples of a distal environment is socio-economic status (SES). A large body of literature demonstrates that SES has a substantial impact on mother-child conversations, parenting styles, and marital relationships (e.g., Bradley \& Corwyn, 2002; Conger \& Donnellan, 2007). For example, high-SES mothers and their children exchanged more utterances, longer words, and more word types at home than did mid-SES mothers and their children (Hoff, 2003; Hart \& Risley, 1995). Fernald, Marchman, and Weisleder (2013) also found an effect of SES on children's vocabulary knowledge; they showed that there were significant disparities in vocabulary and language processing efficiency between infants from higher- and lower-SES families. Since language ability is positively correlated with false belief understanding (e.g., Happé, 1995; Jenkins \& Astington, 1996; Astington \& Jenkins, 1999), children from a higher-SES family would be expected to show greater performance on theory of mind tasks compared to those from a lower-SES family. Likewise, low-SES mothers tend to adopt a harsh parenting style that is more controlling, restrictive, disapproving, less interactive, and conversational with their young children, whereas high-SES mothers tend to be less punitive and more tolerant of interruptions from their children (Hart \& Risley, 1995; Kelley, Sanchez-Hucles, \& Walker, 1993). Finally, research clearly shows that high-SES is positively associated with marital stability and satisfaction (e.g., Conger, Conger, \& Martin, 2010; Karney \& Bradbury, 1995), which leads to optimal parenting behaviors and healthy development of theory of mind.

Despite these findings, direct examinations of the relationship between SES and theory of mind development have failed to show conclusive results. For example, some studies showed that the education level of mothers was positively associated with theory of 
mind development (Cutting \& Dunn, 1999; Jenkins \& Astington, 1996), but others failed to do so (Ruffman et al., 1999). Cutting and Dunn (1999) found that working-class children had lower mean theory of mind scores than middle-class children, even when controlling for language ability. However, Murray, Woolgar, Briers, and Hipwell (1999) failed to replicate those results. To further complicate matters, Hughes et al. (1999) found an association between SES and theory of mind abilities, but that association was not significant when language abilities were taken into account.

These mixed findings might have resulted from the fact that there are several factors to moderate the link between SES and development. For example, since most low-SES families have a double income, children in poorer families will spend less time with their parents. Even when having lunch or dinner, children in low-SES families are more likely to eat alone than those in higher-SES families (Abe, 2008). However, the same may hold true for high-SES families. Kahneman, Krueger, Schkade, Schwarz, and Stone (2006) reported that people who have higher incomes in the United States (more than $\$ 100,000$ ) have less leisure time than people who have lower incomes, due to their busy schedules. Given the link between conversation with parents and children's theory of mind development (e.g., Ensor \& Hughes, 2008; Ruffman et al., 1999), the association between SES and children's development might not be linear, but quadric, moderated by the quality and quantity of parent-child communication (microsystem).

It is also possible that larger family size of low-SES families may explain the mixed results. Unplanned childbearing rates vary by socioeconomic status; unintended birth rates of low-SES mothers are much higher than those of high-SES mothers (e.g., Finer \& Henshaw, 2006). Because of this, children in low-SES families may be more likely to have siblings in their family than high-SES children, and the experience of talking about mental states with siblings may compensate for relatively poor mother-child interaction in low SES families (Hoff, 2003; Hart \& Risley, 1995).

Given that talking about mental states with other children is important for the development of social cognition, the number of peers with whom children interact may influence theory of mind development. In fact, previous studies have shown that variations in talk about mental states with friends (Hughes \& Dunn, 1998) predict individual differences in children's false belief understanding. It would appear that because low-SES children have more siblings than high-SES children, they could have more peers in their community and thus have more opportunities to talk about mental states. However, several studies have shown a relationship between poverty and social exclusion in childhood. That is, children from poor families feel less "fitting in (not feeling different)" or "joining in (being able to participate in social and other activities)" social environments (cf. Buchanan, 2006; Ridge, 2002). Therefore, when children in low-SES families with siblings have little experience to talk about mental states with peers, lack of rich conversation with others may cause the delay in theory of mind acquisition.

Finally, there is a possibility of a gene-SES interaction. Turkheimer, Haley, Waldron, D'Onofrio, and Gottesman (2003) conducted a twin study and found that individual differences in intelligence of children raised in higher-SES families were explained primarily by genes $(72 \%$ of the variation), whereas it was not the case in lower-SES 
families (10\%). Tucker-Drob, Rhemtulla, Harden, Turkheimer, and Fask (2011) also showed similar results for cognitive ability (the Bayley Short Form test of infant mental ability). They argued that this was because twins raised in high-SES families would have abundant chances to develop into their genetic potential (i.e., gene factor), whereas twins raised in low-SES families would have less opportunities to be surrounded by supportive environments that foster cognitive ability. If the same is true for theory of mind, SES could play a more complex role in socio-cognitive development than we might expect.

Culture. Another prominent example of distal environments is culture. Culture infuses virtually every facet of human development. In the 1990s, cultural psychologists suggested that cultural beliefs, values, and ideologies have a significant impact on psychological processes, such as motivation, emotion, and cognition (Markus \& Kitayama, 1991). Since then, numerous cultural differences concerning psychological phenomena have been examined in social, cognitive, and applied psychological research.

Prior to Markus and Kitayama (1991), developmental psychologists had been interested in cultural differences in child development (e.g., Hess \& Azuma, 1991; Hess, Kashiwagi, Azuma, Price, \& Dickson, 1980; Kagan \& Klein, 1973; Kagan et al., 1979). It might be natural for developmental psychologists, especially for those of the postBronfenbrenner generation, to pay attention to cultural effects, because culture is one of the environments that forms proximal environments such as parent's values and beliefs.

In the case of theory of mind development, the models-of agency theory (Markus \& Kitayama, 2004) is of great help to understand the cultural effect. In Western cultural settings (e.g., North America and Western Europe), actions are understood to be chosen by individuals based on their preferences, goals, and intentions independent of social contexts. This implicit understanding of behavior is called the disjoint model of agency. In contrast, in East Asian cultural settings (e.g., Japan, Korea, and China), actions are considered to arise from one's relationships with others and often reflect the need to adjust the self to others' expectations (Morling, Kitayama, \& Miyamoto, 2002), and this implicit understanding of behavior is called the conjoint model of agency. According to the disjoint model of agency in Western cultures, actions are assumed to arise from the self, and individuals are considered responsible for the consequences of actions, which originate from and depend primarily on themselves. According to the conjoint model of agency in Eastern cultures, actions are assumed to be grounded in relationships, and individuals are considered to be responsible for consequences of actions that arise from and are grounded in their relationships with others.

These models of agency likely have an influence on how children develop their ability to perceive differing cognition and their views of the mind. Specifically, children from Western cultural contexts would easily distinguish another mind from their own mind, since they view the mind as being independent, autonomic, and separated from each other. In contrast, children from Eastern cultural contexts would find difficulty in distinguishing others' mind from their own mind, since they view the mind as being interdependent, embedded in, and connected with each other. As a consequence, the development of theory of mind among children from Eastern cultural contexts should be more delayed than children from Western cultural contexts. 
In fact, some studies have found partial support for this hypothesis (Hughes et al., 2014; Liu, Wellman, Tardif, \& Sabbagh, 2008). For example, Liu et al. (2008) compared Chinese children (i.e., from mainland China and Hong Kong) and North American children (i.e., children in the United States and Canada), and found that children from Canada develop theory of mind the earliest, those from the United States and mainland China came next, and those from Hong Kong were the last. Hughes et al. (2014) compared Japanese, Italian, and British children, and reported that Japanese children developed theory of mind later than British children, again suggesting cultural influence on theory of mind.

Naito and Koyama (2006) examined why young Japanese children failed to pass the false belief task and revealed that Japanese children tended to attribute people's behavior not to internal states, but to contextual and interpersonal cues, such as observable behaviors, utterances, and social rules inferred from the situation. These findings are consistent with the idea of cultural models of agency, which suggests cultural differences in attributions. In other words, Western people tend to attribute events to causes internal to the object or person due to the disjoint model of agency, whereas Asians tend to attribute causality to the context or situation due to the conjoint model of agency (e.g., Nisbett \& Miyamoto, 2005).

Moreover, there are several points of evidence supporting the notion of an indirect influence of cultural beliefs on the development of theory of mind. For example, American mothers were found to be more likely to value their children's behaviors that respect their own rights, such as self-assertion and standing up for one's rights. In contrast, Japanese mothers had more concerns about whether their children were engaged in behaviors that respect social order and social harmony, such as self-control, compliance to authority, and social interactions (Hess et al., 1980). Likewise, Japanese mothers have a tendency to stay physically and mentally close to their infants for a long time (Hess \& Azuma, 1991), whereas infants are seen as separate individuals from birth in the United States (Chen \& Miyake, 1986). These parental styles might foster how one views the self or others' minds in a way consistent with each set of cultural values: connected, interdependent views in Eastern cultural contexts, and autonomic, independent views in Western cultural contexts.

In addition to cultural values and beliefs, which would be transmitted through motherchild interactions, there are several potential socio-ecological factors to explain the cultural difference. For example, people are more likely to move in the United States than in Japan. Almost half of Americans changed their residential community between 1995 and 2000 (Schmitt, 2001), whereas $28.1 \%$ of the Japanese population moved during the same 5-year period (Statistics Bureau \& Statistics Center of Japan, 2001). In such a highly mobile environment, children are more likely to have various meetings and partings than in a low mobile environment, providing more experience to differentiate others from themselves. In fact, Oishi, Lun, and Sherman (2007) showed that residential mobility strengthened the relative centrality of personal self (a term interchangeable with disjoint model of agency) compared to collective self (a term interchangeable with conjoint model of agency). Cultural differences in theory of mind development may in part be the result of residential mobility because experience of interacting with many more people scaffold children toward a greater awareness of others' mind.

Language use may also influence theory of mind development. For example, Japanese 
mothers communicate with their infants much more by touch and less by vocalization than do American mothers (Saarni, Campos, Camras, \& Witherington, 2006). Moreover, in Japanese, mental state terms are rarely used in mothers' speech to children and children's speech (Uchida, Murakami, \& Fernald, 2006). Japanese mothers of preschoolers use mental state terms, such as beliefs and uncertainty (i.e., "maybe", "wonder") less frequently than American mothers (Matsui, McCagg, Yamamoto, \& Murakami, 2004). These findings suggest that children in the United States are more likely to be aware of mental states than children in Eastern countries.

In addition, it is possible that linguistic structures influence the development of theory of mind. Gopnik and Choi (1990), for example, argued that the vocabulary spurt (i.e., the sudden increase in the productive vocabulary) emerged several mounth later in Korean infants compared to American infants due to a linguistic difference concerning emphasis on nouns. In other words, in Korean, nouns can be dropped from a sentence, but this is not the case in English. Moreover, the word placed at the end of sentence, which is perceptually prominent, is typically a noun in English and a verb in Korean. They argued that these linguistic features influence the onset of the vocabulary spurt. Given that language ability is positively correlated with the development of theory of mind, it is also possible that such linguistic structures explain cultural differences in theory of mind development between English-speaking-Western countries and Japan.

As indicated, however, note that there also exist large variations within Eastern and Western countries (Liu et al., 2008; Lecce \& Hughes, 2010). Lecce and Hughes (2010) reported that Italian preschoolers showed a significant delay in theory of mind, compared to British preschoolers. Hughes et al. (2014) replicated the finding, and also showed that there was no significant difference between Italian children and Japanese children. Hughes et al. (2014) attributed one of the reasons to the timing of entering school. Children begin formal schooling at age 6 in Italy and Japan, which is at least a year later than their British counterparts. Since schooling offers both increased contact with peers and exposure to pedagogical situations, which encourage reflective self-awareness (Astington, Pelletier, \& Homer, 2002), early schooling may contribute to the earlier development of theory of mind. Although this explanation is only speculative, future investigation will likely reveal whether formal societal systems as well as cultural systems do in fact have significant impacts on the development of children's understanding of mental states.

\section{Time and theory of mind}

Longitudinal studies. Bronfenbrenner added chronosystem to his original model to acknowledge that human ecologies change over time. There are numerous longitudinal studies that have investigated children's theory of mind and its link with other related indices, such as language ability, executive function, sensitivity to criticism, and social interaction over time (e.g., Astington \& Jenkins, 1999; Cutting \& Dunn, 2002; Ensor et al., 2013; Hughes \& Dunn, 1998; Hughes \& Ensor, 2007; Jenkins \& Astington, 2000; Koyasu, Goushiki, \& Hattori, 2003; Lecce, Caputi, \& Hughes, 2011; Lecce, Caputi, \& Pagnin, 2014; Ozonoff \& McEvoy, 1994; Ruffman et al., 2002). For example, Lecce and her colleagues found that children's theory of mind ability at 5-years of age predicted their 
sensitivity to criticism, and that sensitivity to criticism at 6-years of age mediated the effect of theory of mind at 5-years of age on academic achievement at 7- and 10-years of age (Lecce et al., 2011, 2014).

Cohort effects. To our knowledge, there is no specific research that has investigated whether theories of mind differ from generation to generation. This is because research on theory of mind span only 30 years and there has not been enough time to investigate possible cohort effects. However, family structure and lifestyle has drastically changed over these three decades, and it is possible that there may be a cohort effect on children's social cognition. In Japan, for example, the number of children has gradually decreased in the post World War II era; the total fertility rate in Japan was 4.54 in 1947 and 1.39 in 2011 (Ministry of Health, Labor and Welfare, 2012). In the case of Tokyo, the capital city of Japan, it dropped down to 1.06 in 2011, suggesting that children of today, especially those who live in urban cities, have fewer opportuninities to interact with siblings. Given that some empirical evidence suggests that interaction with siblings may have a positive influence on the development of theory of mind (e.g., Jenkins \& Astington, 1996; Lewis et al., 1996), there might be a difference in theory of mind performance between today's children and children in the past.

Mother-child relationships have also changed in the past three decades. The Ministry of Internal Affairs and Communications (2013) reported that female employment in Japan has risen to $60 \%$ and that almost half $(52.4 \%)$ of working women between 25 - to 44 -yearsold have one or more children. However, the majority of Japanese mothers are more or less facing strong pressures to be a main provider of child care and household care because many Japanese still uphold the traditional idea that a mother's continuous presence is critical for a child's development during their first 3 years (Sansaiji-Sinwa). Japanese fathers are still not engaged in child care, although the Japanese government is running an active media campaign to encourage a departure from the myth of "workaholic fathers" and "full-time mothers" to "ikumen (fathers who participate in child care)" (Holloway\& Nagase, 2014). Such pressure on working mothers' commitment to child care without adequate support would affect maternal mental health and time management, which in turn, would likely affect the quantity and quality of mother-child communication.

Moreover, after World War II, the reforms of the educational system opened up for women to access all levels of schooling, including college and university. Given that some studies have shown that the education level of mothers is positively associated with their children's theory of mind development (Cutting \& Dunn, 1999; Jenkins \& Astington, 1996), this educational change might also indirectly affect children's social cognition and social behaviors. Findings by Naito and Koyama (2006) suggest this: children living in a suburban city (with smaller family size and higher maternal education background) performed better than children living in a provincial city in theory of mind tasks.

Outside of Japan, such as in European societies, due to the influence of education, industrial development, and urban life, parenting has become more individualistic and egocentric (Music, 2011). For example, in Germany, beacause of the historical change, the nature of mother-baby interaction during free-play scenario has changed from the late 1970 s to 2000. Compared to mothers in the late 1970s, mothers in 2000 gave less bodily 
contact, encouraged more face-to-face contact, used more object manipulation and toys, and made greater use of language that supported autonomy when they interacted with their three-month-old babies (Keller \& Lamm, 2005). In other words, over this period, the distal style (e.g., face-to-face interaction) significantly increased, and proximal parenting (i.e., body contact) significantly decreased. Empirical studies have not yet revealed whether and how historical change might influence children's theory of mind development. It is therefore worth examining children's socio-cognitive development in developing countries (e.g., China) where industrialization is rapidly growing.

As discussed in this article, there is plenty of evidence showing that children's environment (e.g., maternal talk, siblings, family size, parental education, and residential area) influence their theory of mind performance in their preschool years. As societal settings change, such environments could also change. In this sense, large cohort research will be a promising project to investigate possible environmental effects on children's socio-cognitive development.

\section{CONClusion AND Future Directions}

Environments, which include families, communities, and societies, influence human development in many ways. Child socio-cognitive development occurs as a part of a correlated web of social environment, including parenting, maternal talk, marital relationships, socio-economic status, culture, and educational system. These environments change over time and contribute to patterns of an individual's development. As we have reviewed in this article, previous studies have tried to reveal children's socio-cognitive development by investigating both the direct and indirect environmental influences. Although this review has been restricted to theory of mind development, we can apply Bronfenbrenner's socio-ecological view to understand children's developing mind and social behaviors more broadly.

One example demonstrating an ecological perspective in the applied context is the "first-grader problem," a well-known behavioral problem in Japan. This problem can be understood and discussed in terms of historic change in the education system. The firstgrader problem is a series of problem behaviors, including being difficult to engage in group activity, remaining seated during the class, carefully listening to the teacher, and following the teachers' instruction. After entering elementary school, some children continue these problematic behaviors over several months. The problem has drawn the attention of educators, psychologists, and sociologists over the last 15 years. For most of that time, the majority of people in the field of education (i.e., teachers and school board members) have thought that the first-grader problem could be due to inadequate parenting at home, children's immaturity in self control, and developmental disability (Tokyo Gakugei University, 2010). In other words, they have tried to understand this problem from the individual's personal characteristics or the family (i.e., the most proximal micro systems).

However, there is another view that has been suggested by scholars (i.e., sociologist 
and educationalist) that the problem may be attributable to the discrepant educational systems between preschool and elementary school. More specifically, the Japanese public education system dates back to the Meiji restoration. The Meiji government in Japan created the first Ministry of Education in 1871, and developed the school system based on the American model and the centrally-controlled administrative system based on the French model. Since then, the aims and the curriculum have essentially remained unchanged in elementary schools where there is a common curriculum for all students under a singletrack system. In elementary school education, all children proceed together at the same time. On the other hand, in preschool education, gradual change has occurred in the last 25 years. In the education provided in kindergarten and nursery school, children are allowed to proceed in activities at their own pace and based on their own interest (Ministry of Education, Culture, Sports, Science and Technology, 2008). Preschool teachers try not to instruct children what to do and what to learn. The prevailing philosophy of childcare in Japan is based on the notion of "doing nothing but watching and waiting" rather than taking a heavy-handed and directive management approach (Hayashi, 2011). Teachers rarely intervene in what children do, because they believe that children know their abilities and learn by themselves. Indeed, Niwa, Sakai, and Fujie (2004) revealed that preschool teachers emphasize the importance of children's independence and willingness more than elementary school teachers. Consequently, children who are confused in between preschool and elementary school contexts, and fail to adapt to such ecological change, might show the first-grader problem - that is, the first-grader problem might not be solely due to the individual's characteristic issues or family difficulties, but due in part to historical change in pre-school teaching methods being used.

These investigations indicate that the first-grader problem is evoked by multiple layers of environments from the most proximal level (i.e., family) to the most distal level (i.e., historical changes), and their interactions over time. From this perspective, most recently, several local governments and schools in Japan have made efforts to bridge the gap between pre-school and elementary school education. This is one case in which a socio-ecological view provides useful information in understanding children's mind and social behavior in educational contexts.

In this article, we have reviewed developmental research investigating children's socio-cognitive development, especially concerning theory of mind from the socioecological perspective. Bronfenbrenner's ecological systems theory provides researchers with a number of fruitful directions for future research, including large cohort research to determine the sources of influence leading to different developmental processes and external correlates across age, community, culture, and era. As we have seen in this review, a certain environmental factor has quite different meanings for children with different backgrounds (Bronfenbrenner, 1994; Drillien, 1957, 1964). The socio-ecological approach to developmental issues would help people who are either directly or indirectly engaged in child care, social support, and education (e.g., teachers, parents, counselers, and policy makers) to better understand children's mind and social behavior from multifaced perspectives, and ultimately provide solutions to address various educational and developmental issues. 


\section{REFERENCE}

Abe, A. 2008. Child poverty: Rethinking fairness in Japan. Tokyo: Iwanami Shoten. (In Japanese)

Astington, J. W., \& Jenkins, J. M. 1999. A longitudinal study of the relation between language and theoryof-mind development. Developmental psychology, 35, 1311-1320.

Astington, J. W., Pelletier, J., \& Homer, B. 2002. Theory of mind and epistemological development: The relation between children's second-order false-belief understanding and their ability to reason about evidence. New Ideas in Psychology, 20, 131-144.

Baron-Cohen, S., Leslie, A. M., \& Frith, U. 1985. Does the autistic child have a "theory of mind"? Cognition, 21, 37-46.

Belsky, J. 1981. Early human experience: A family perspective. Developmental Psychology, 17, 3-23.

Belsky, J., Youngblade, L., Rovine, M., \& Volling, B. 1991. Patterns of marital change and parent-child interaction. Journal of Marriage and the Family, 53, 487-498.

Bradley, R. H., \& Corwyn, R. F. 2002. Socioeconomic status and child development. Annual Review of Psychology, 53, 371-399.

Bronfenbrenner, U. 1977. Toward an experimental ecology of human development. American. Psychologist, 32, 513-531.

Bronfenbrenner, U. 1979. The ecology of human development: Experiments by nature and design. Cambridge, MA: Harvard University Press.

Bronfenbrenner, U. 1994. Ecological models of human development. In T. Husen \& T. N. Postlethwaite (Eds.), International encyclopedia of education. Vol. 3 (2nd ed., pp. 1643-1647). Oxford, England: Elsevier. (Reprinted from Readings on the development of children, pp. 37-43, by M. Gauvain \& M. Cole, Eds., New York: Freeman)

Bronfenbrenner, U. 1999. Environments in developmental perspective: Theoretical and operational models. In S. L. Friedman \& T. D. Wachs (Eds.), Measuring environment across the life span: Emerging methods and concepts (pp. 3-28). Washington, DC: American Psychological Association Press.

Bronfenbrenner, U. 2005. Making human beings human. Thousand Oaks, CA: Sage.

Bronfenbrenner, U., \& Crouter, A. C. 1983. The evolution of environmental models in developmental research. In P. H. Mussen (Series Ed.) \& W. Kessen (Vol. Ed.), Handbook of child psychology: Vol. 1. History, theory, and methods (4th ed., pp. 357-414). New York: Wiley.

Bronfenbrenner, U., \& Morris, P. A. 2006. The bioecological model of human development. In W. Damon \& R. M. Lerner (Eds.), Handbook of child psychology: Vol. 1. Theoretical models of human development (6th ed., pp. 793-828). New York: Wiley.

Buchanan, A. 2006. Children aged 0-13 at risk of social exclusion: Impact of government policy in England and Wales. Children and Youth Services Review, 28, 1135-1151.

Call, J., \& Tomasello, M. 2008. Does the chimpanzee have a theory of mind? 30 years later. Trends in Cognitive Sciences, 12, 187-192.

Cassidy, K. W., Fineberg, D. S., Brown, K., \& Perkins, A. 2005. Theory of mind may be contagious, but you don't catch it from your twin. Child Development, 76, 97-106.

Cassidy, K. W., Werner, R. S., Rourke, M., Zubernis, L. S., \& Balaraman, G. 2003. The relationship between psychological understanding and positive social behavior. Social Development, 12, 198-221.

Caspi, A., McClay, J., Moffitt, T. E., Mill, J., Martin, J., Craig, I. W., et al. 2002. Role of genotype in the cycle of violence in maltreated children. Science, 297, 851-854.

Chen, S., \& Miyake. K. 1986. Japanese studies of child development. In H. Stevenson, H. Azuma, \& K. Hakuta (Eds.), Child development and education in Japan (pp. 135-146). New York: Freeman.

Cole, K., \& Mitchell, P. 2000. Siblings in the development of executive control and a theory of mind. British Journal of Developmental Psychology, 18, 279-295.

Conger, R. D., Conger, K. J., \& Martin, M. J. 2010. Socioeconomic status, family processes, and individual development. Journal of Marriage and Family, 72, 685-704.

Conger, R. D., \& Donnellan, M. B. 2007. An interactionist perspective on the socioeconomic context of human development. Annual Review of Psychology, 58, 175-199.

Cowan, C. P., \& Cowan, P. A. 1992. When partners become parents: The big life change for couples. New York: Basic Books.

Cutting, A. L., \& Dunn, J. 1999. Theory of mind, emotion understanding, language and family background: 
Individual differences and interrelations. Child Development, 70, 853-865.

Cutting, A. L., \& Dunn, J. 2002. The cost of understanding other people: Social cognition predicts young children's sensitivity to criticism. Journal of Child Psychology and Psychiatry, 43, 849-860.

Doherty, M. J. 2009. Theory of mind: How children understand others 'thoughts and feelings. Hove, England: Psychology Press.

Drillien, C. M. 1957. The social and economic factors affecting the incidence of premature birth. An International Journal of Obstetrics and Gynaecology, 64, 161-184.

Drillien, C. M. 1964. The growth and development of the prematurely born infant. Edinburgh, England: Livingstone.

Dunn, J., Brown, J., Slomkowski, C., Tesla, C., \& Youngblade, L. 1991. Young children's understanding of other people's feelings and beliefs: Individual differences and their antecedents. Child Development, 62, 1352-1366.

Emery, R. E. 1982. Interparental conflict and the children of discord and divorce. Psychological Bulletin, 92, 310-330.

Ensor, R., Devine, R. T., Marks, A., \& Hughes, C. 2013. Mothers' cognitive references to 2-year-olds predict theory of mind at ages 6 and 10. Child Development. doi: 10.1111/cdev.12186

Ensor, R., \& Hughes, C. 2008. Content or connectedness? Mother-child talk and early social understanding. Child Development, 79, 201-216.

Fahie, C. M., \& Symons, D. K. 2003. Executive functioning and theory of mind in children clinically referred for attention and behavior problems. Journal of Applied Developmental Psychology, 24, 51-73.

Fernald, A., Marchman, V. A., \& Weisleder, A. 2013. SES differences in language processing skill and vocabulary are evident at 18 months. Developmental Science, 16, 234-248.

Finer, L. B., \& Henshaw, S. K. 2006. Disparities in rates of unintended pregnancy in the United States, 1994 and 2001. Perspectives on Sexual and Reproductive Health, 38, 90-96.

Goldberg,W. A., \& Easterbrooks, M. A. 1984. Role of marital quality in toddler development. Developmental Psychology, 20, 504-514.

Gopnik, A., \& Astington, J. W. 1988. Children's understanding of representational change and its relation to the understanding of false belief and the appearance-reality distinction. Child Development, 59, 26-37.

Gopnik, A., \& Choi, S. 1990. Do linguistic differences lead to cognitive differences? A cross-linguistic study of semantic and cognitive development. First Language, 10, 199-215.

Happé, F. G. 1995. The role of age and verbal ability in the theory of mind task performance of subjects with autism. Child Development, 66, 843-855.

Hart, B., \& Risley, T. R. 1995. Meaningful differences in the everyday experience of young American children. Baltimore: Paul H. Brookes Publishing.

Hayashi, A. 2011. Japanese preschool educators'cultural practices and beliefs about the pedagogy of socialemotional development. Dissertation, Arizona State University.

Hess, R. D., \& Azuma, H. 1991. Cultural support for schooling: Contrasts between Japan and the United States. Educational Researcher, 20, 2-9.

Hess, R. D., Kashiwagi, K., Azuma, H., Price, G. G., \& Dickson, W. P. 1980. Maternal expectations for mastery of developmental tasks in Japan and the United States. International Journal of Psychology, 15, 259-271.

Hoff, E. 2003. The specificity of environmental influence: Socioeconomic status affects early vocabulary development via maternal speech. Child Development, 74, 1368-1378.

Holloway, S. D., \& Nagase, A. 2014. Child rearing in Japan. In H. Selin (Ed.), Parenting across cultures: Childrearing, motherhood and fatherhood in non-Western cultures (pp. 59-76). Netherlands: Springer.

Hughes, C., Deater-Deckard, K., \& Cutting, A. L. 1999. “Speak roughly to your little boy?" Sex differences in the relations between parenting and preschoolers' understanding of mind. Social Development, 8 , 143-160.

Hughes, C., Devine, R.T., Ensor, R., Koyasu, M., Mizokawa, A., \& Lecce, S. 2014. Lost in translation? Comparing British, Japanese, and Italian children's theory-of-mind performance. Child Development Research, Article ID 893492.

Hughes, C., \& Dunn, J. 1998. Understanding mind and emotion: Longitudinal associations with mental-state talk between young friends. Developmental Psychology, 34, 1026-1037.

Hughes, C., Dunn, J., \& White, A. 1998. Trick or treat?: Uneven understanding of mind and emotion and 
executive dysfunction in "hard-to-manage" preschoolers. Journal of Child Psychology and Psychiatry, 39, 981-994.

Hughes, C., \& Ensor, R. 2007. Executive function and theory of mind: Predictive relations from ages 2 to 4. Developmental psychology, 43, 1447-1459.

Hughes, C., \& Leekam, S. 2004. What are the links between theory of mind and social relations? Review, reflections and new directions for studies of typical and atypical development. Social Development, 13, 590-619.

Jenkins, J. M., \& Astington, J. W. 1996. Cognitive factors and family structure associated with theory of mind development in young children. Developmental Psychology, 32, 70-78.

Jenkins, J. M., \& Astington, J. W. 2000. Theory of mind and social behavior: Causal models tested in a longitudinal study. Merrill-Palmer Quarterly, 46, 203-220.

Kahneman, D., Krueger, A. B., Schkade, D., Schwarz, N., \& Stone, A. A. 2006. Would you be happier if you were richer? A focusing illusion. Science, 312, 1908-1910.

Kagan, J., \& Klein, R. E. 1973. Cross-cultural perspectives on early development. American Psychologist, 28, 947-961.

Kagan, J., Klein, R. E., Finley, G. E., Rogoff, B., Nolan, E., \& Greenbaum, C. 1979. A cross-cultural study of cognitive development. Monographs of the Society for Research in Child Development, 44, 1-77.

Karney, B. R., \& Bradbury, T. N. 1995. Assessing longitudinal change in marriage: An introduction to the analysis of growth curves. Journal of Marriage and Family, 57, 1091-1108.

Keller, H., \& Lamm, B. 2005. Parenting as the expression of sociohistorical time: The case of German individualisation. International Journal of Behavioral Development, 29, 238-246.

Kelley, M. L., Sanchez-Hucles, J., \& Walker, R. R. 1993. Correlates of disciplinary practices in working- to middle-class African-American mothers. Merrill-Palmer Quarterly, 39, 252-264.

Koyasu, M., Goushiki, T., \& Hattori, K. 2003. A longitudinal study of "theory of mind" and its related abilities in a mixed class kindergarten. Kyoto University research studies in education, 49, 1-21. (In Japanese)

Lecce, S., \& Hughes, C. 2010. The Italian job?: Comparing theory of mind performance in British and Italian children. British Journal of Developmental Psychology, 28, 747-766.

Lecce, S., Caputi, M., \& Hughes, C. 2011. Does sensitivity to criticism mediate the relationship between theory of mind and academic achievement? Journal of Experimental Child Psychology, 110, 313-331.

Lecce, S., Caputi, M., \& Pagnin, A. 2014. Long-term effect of theory of mind on school achievement: The role of sensitivity to criticism. European Journal of Developmental Psychology, 11, 305-318.

Lewis, C., Freeman, N. H., Kyriakidou, C., Maridaki-Kassotaki, K., \& Berridge, D. M. 1996. Social influences on false belief access: Specific sibling influences or general apprenticeship? Child Development, 67, 2930-2947.

Liu, D., Wellman, H. M., Tardif, T., \& Sabbagh, M. A. 2008. Theory of mind development in Chinese children: A meta-analysis of false-belief understanding across cultures and languages. Developmental psychology, 44, 523-531.

Markus, H. R., \& Kitayama, S. 1991. Culture and the self: Implications for cognition, emotion, and motivation. Psychological Review, 98, 224-253.

Markus, H. R., \& Kitayama, S. 2004. Models of agency: Sociocultural diversity in the construction of action. In V. Murphy-Berman \& J. J. Berman (Eds.), Nebraska symposium on motivation: Vol. 49. Crosscultural differences in perspectives on the self (pp. 1-57). Lincoln: University of Nebraska Press.

Matsui, T., McCagg. P., Yamamoto, T., \& Murakami, Y. 2004. Japanese preschoolers' early understanding of (un)certainty: A cultural perspective on the role of language in development of theory of mind. Proceedings of the 28th Annual Boston University Conference on Language Development, 350-362.

Mayes, L., \& Lewis, M. (Eds.). 2012. The Cambridge handbook of environment in human development. New York: Cambridge University Press.

Miller, S. A. 2012. Theory of mind: Beyond the preschool years. New York: Psychology Press.

Ministry of Education, Culture, Sports, Science and Technology. 2008. Shin yochien kyoiku yoryo [National curriculum standards for Kindergartens]. Tokyo: Ministry of Education, Culture, Sports, Science and Technology in Japan. (In Japanese)

Ministry of Health, Labor and Welfare. 2012. Handbook of health and welfare statistics 2012. Retrieved January 20, 2014, from http://www.mhlw.go.jp/english/database/db-hh/1-2.html

Ministry of Internal Affairs and Communications. 2013. Annual report on the labour force survey (1993, 
1998-2012). Retrieved January 20, 2014, from http://winet.nwec.jp/toukei/save/xls/L104010.xls (In Japanese)

Mizokawa, A., \& Koyasu, M. 2011. Understanding false beliefs, hidden emotions, and social interactions among five- and six-year-olds. The Japanese Journal of Developmental Psychology, 22, 168-178. (In Japanese with English abstract)

Morling, B., Kitayama, S., \& Miyamoto, Y. 2002. Cultural practices emphasize influence in the United States and adjustment in Japan. Personality and Social Psychology Bulletin, 28, 311-323.

Morino, M. 2005. Preschoolers' theory of mind, understanding of emotions, and interactions with peers. The Japanese Journal of Developmental Psychology, 16, 36-45. (In Japanese with English abstract)

Murray, L., Woolgar, M., Briers, S., \& Hipwell, A. 1999. Children's social representations in dolls' house play and theory of mind tasks, and their relation to family adversity and child disturbance. Social Development, 8, 179-200.

Music, G. 2011. Nurturing natures: Attachment and children's emotional, sociocultural and brain development. Hove, England: Psychology Press.

Naito, M., \& Koyama, K. 2006. The development of false-belief understanding in Japanese children: Delay and difference? International Journal of Behavioral Development, 30, 290-304.

Nisbett, R. E., \& Miyamoto, Y. 2005. The influence of culture: Holistic versus analytic perception. Trends in Cognitive Sciences, 9, 467-473.

Niwa, S., Sakai, A., \& Fujie, Y. 2004. An attitude survey about cooperation between nursery school, kindergarten and elementary school: For better cooperation between nursery school, kindergarten and elementary school. Bulletin of the Research Center for Child and Adolescent Development and Education, Ochanomizu University, 2, 39-50. (In Japanese)

Oishi, S., Lun, J., \& Sherman, G. D. 2007. Residential mobility, self-concept, and positive affect in social interactions. Journal of Personality and Social Psychology, 93, 131-141.

Onishi, K. H., \& Baillargeon, R. 2005. Do 15-month-old infants understand false beliefs? Science, 308, $255-258$.

Ozonoff, S., \& McEvoy, R. E. 1994. A longitudinal study of executive function and theory of mind development in autism. Development and Psychopathology, 6, 415-431.

Pears, K. C., \& Moses, L. J. 2003. Demographics, parenting, and theory of mind in preschool children. Social Development, 12, 1-20.

Perner, J., Ruffman, T., \& Leekam, S. R. 1994. Theory of mind is contagious: You catch it from your sibs. Child Development, 65, 1228-1238.

Peterson, C. C. 2000. Kindred spirits: Influences of siblings' perspectives on theory of mind. Cognitive Development, 15, 435-455.

Peterson, C. C., \& Siegal, M. 1999. Representing inner worlds: Theory of mind in autistic, deaf, and normal hearing children. Psychological Science, 10, 126-129.

Peterson, C. C., \& Siegal, M. 2000. Insights into theory of mind from deafness and autism. Mind \& Language, 15, 123-145.

Peterson, C., \& Slaughter, V. 2003. Opening windows into the mind: Mothers' preferences for mental state explanations and children's theory of mind. Cognitive Development, 18, 399-429.

Plomin, R. 1994. Genetics and experience: The interplay between nature and nurture. Vol 6. Thousand Oaks, CA: Sage.

Plomin, R., Reiss, D., Hetherington, E. M., \& Howe, G. W. 1994. Nature and nurture: Genetic contributions to measures of the family environment. Developmental Psychology, 30, 32-43.

Premack, D., \& Woodruff, G. 1978. Does the chimpanzee have a theory of mind? Behavioral and Brain Sciences, 1, 515-526.

Ridge, T. 2002. Childhood poverty and social exclusion: From a child's perspective. Bristol, England: The Policy Press.

Ruffman, T., Perner, J., Naito, M., Parkin, L., \& Clements, W. A. 1998. Older (but not younger) siblings facilitate false belief understanding. Developmental Psychology, 34, 161-174.

Ruffman, T., Perner, J., \& Parkin, L. 1999. How parenting style affects false belief understanding. Social Development, 8, 395-411.

Ruffman, T., Slade, L., \& Crowe, E. 2002. The relation between children's and mothers' mental state language and theory-of-mind understanding. Child Development, 73, 734-751. 
Saarni, C., Campos, J. J., Camras, L., \& Witherington, D. 2006. Emotional development: Action, communication, and understanding. In W. Damon \& R. M. Lerner (Series Eds.) and N. Eisenberg (Vol. Ed.), Handbook of child psychology: Vol. 3. Social, emotional, and personality development (6th ed., pp. 226-299). New York: John Wiley \& Sons.

Sagi, A., \& Hoffman, M. L. 1976. Empathic distress in the newborn. Developmental Psychology, 12, 175176.

Schmitt, E. (2001, August 6). Census data show a sharp increase in living standard. New York Times. Retrieved January 20, 2014, from http://www.nytimes.com/2001/08/06/national/06CENS.html

Slaughter, V., Dennis, M. J., \& Pritchard, M. 2002. Theory of mind and peer acceptance in preschool children. British Journal of Developmental Psychology, 20, 545-564.

Slomkowski, C., \& Dunn. J. 1996. Young children's understanding of other people's beliefs and feelings and their connected communication with friends. Developmental Psychology, 32, 442-447.

Southgate, V., Senju, A., \& Csibra, G. 2007. Action anticipation through attribution of false belief by 2-yearolds. Psychological Science, 18, 587-592.

Statistics Bureau \& Statistics Center of Japan. 2001. Jumin kihondaityou jinkoido no genjou-heisei12nen [A report on population move based on residential certificate: Current situations with the population move_year 2000]. Retrieved January 20, 2014, from http://www.stat.go.jp/data/idou/ sokuhou/nen/ index.htm (In Japanese)

Tokyo Gakugei Unieversity. 2010. Shouich problem kenkyu suisin project houkokusho [A report on the firstgrader problem research promotion project]. Retrieved January 20, 2014, from http://www.u-gakugei. ac.jp/ shouichi/report/index.html (In Japanese)

Tomasello, M., Kruger, A. C., \& Ratner, H. H. 1993. Cultural learning. Behavioral and Brain Sciences, 16, 495-511.

Tucker-Drob, E. M., Rhemtulla, M., Harden, K. P., Turkheimer, E., \& Fask, D. 2011. Emergence of a gene $\times$ socioeconomic status interaction on infant mental ability between 10 months and 2 years. Psychological Science, 22, 125-133.

Turkheimer, E., Haley, A., Waldron, M., D’Onofrio, B., \& Gottesman, I. I. 2003. Socioeconomic status modifies heritability of IQ in young children. Psychological Science, 14, 623-628.

Uchida, N., Murakami, Y., \& Fernald, A. 2006. Evaluation of word-learning constraints: Japanese and American preschoolers' sensitivity to speaker certainty and uncertainty in word-learning. In N. Uchida, A. Ishiguchi, K. Aoki, A. Sakai, H. Mimizuka, H. Fujisaki, et al. (Eds.), Research monograph: Studies of human development (pp. 9-20), Tokyo: Ochanomizu University, The 21st century COE program "Studies of Human Development from Birth to Death".

Vygotsky, L. S. 1978. Mind in society: The development of higher psychological processes. In M. Cole, V. John-Steiner, S. Scribner, \& E. Souberman (Eds.), Cambridge, MA: Harvard University Press. (Original work published 1930, 1933, and 1935).

Watson, A. C., Nixon, C. L., Wilson, A., \& Capage, L. 1999. Social interaction skills and theory of mind in young children. Developmental Psychology, 35, 386-391.

Wellman, H. M., Cross, D., \& Watson, J. 2001. Meta-analysis of theory-of-mind development: The truth about false belief. Child Development, 72, 655-684.

Wimmer, H., \& Perner, J. 1983. Beliefs about beliefs: Representation and constraining function of wrong beliefs in young children's understanding of deception. Cognition, 13, 103-128. 